\title{
Validation and method development for Identification of phenolic acids in ethanolic extract of Vitex trifolia.L using HPLC
}

Monapati Suchitra ${ }^{1}$ Binoy Varghese Cheriyan ${ }^{1}$, Manjunath katagi ${ }^{2}$

1. Department of Pharmaceutical Chemistry and Analysis, School of Pharmaceutical Sciences, VISTAS, Chennai, India.

2. Department of Pharmaceutical Chemistry, Bapuji Pharmacy College, Davanagere, Karnataka, India.

- Introduction

- V. trifolia belongs to the genus Vitex, family Verbenacae. It is a shrub and since it is rich in phytochemical constituents like phenolic acids, flavonoids, sterols and terpenoids it has wide pharmacological actions like anti-inflammatory,anti-cancer, anti helminthic etc. In the present study, method developed for identification and validation of three known phenolic acids (p-methoxy benzoic acid, p-hydroxy benzoic acid, and p- coumaric acid) from ethanolic extract of Vitex trifolia.L using high performance liquid.

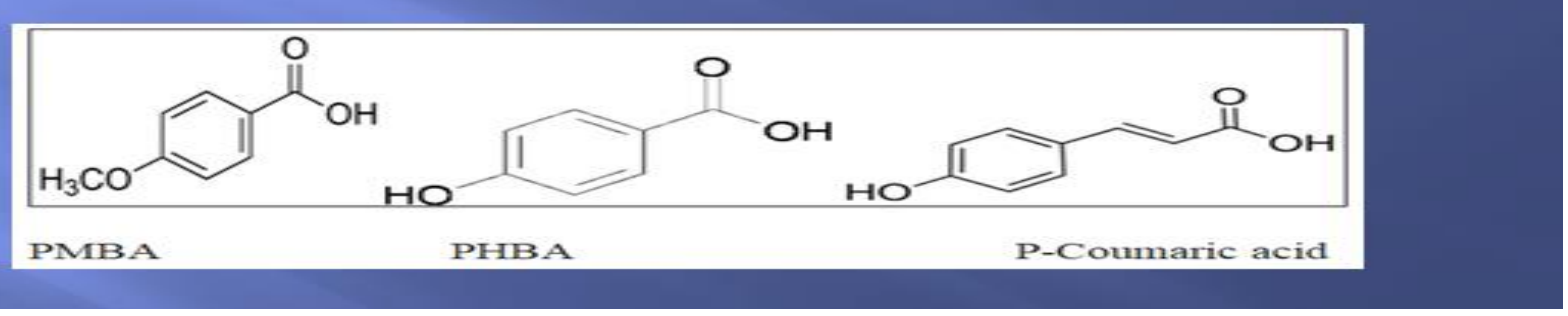

\section{- Methodology}

- Leaves of $V$. trifolia were collected and shade dried in shade for seven days, coarsely powdered using mechanical device. About 500g of coarsely powdered v.trifolia was extracted with ethanol using soxhlet apparatus for $36 \mathrm{hrs}$.

- Chromatographic conditions of HPLC

- The method developed was achieved using acetic acid: acetonitrile $(1 \% \mathrm{v} / \mathrm{v})$ as the mobile phase in an isocratic elution mode. Accurately $500 \mathrm{ml}$ of Buffer and Acetonitrile were mixed and degassed in an ultrasonic water bath for 10 minutes and then filtered through $0.45 \mu$ filter under vacuum filtration. Inertsil ODS (150 x 4.6mm, $5 \mu \mathrm{m})$ was found to be ideal as it gave good peak shape and resolution at $1.0 \mathrm{ml} / \mathrm{min}$ flow and detection wavelength at $254 \mathrm{~nm}$. The $20 \mu \mathrm{l}$ of sample was injected and the temperature was maintained at $25^{\circ} \mathrm{c}$. The concentrations of PMBA, PHBA and P-Coumaric acid were calculated by comparing with the integrated peak areas of PMBA, PHBA and P-Coumaric acid in the extract chromatograms with that of a standard curve prepared for corresponding standard solution. For analytical recovery, plant extract was mixed with known amount of standard and re chromatographed.

- Results

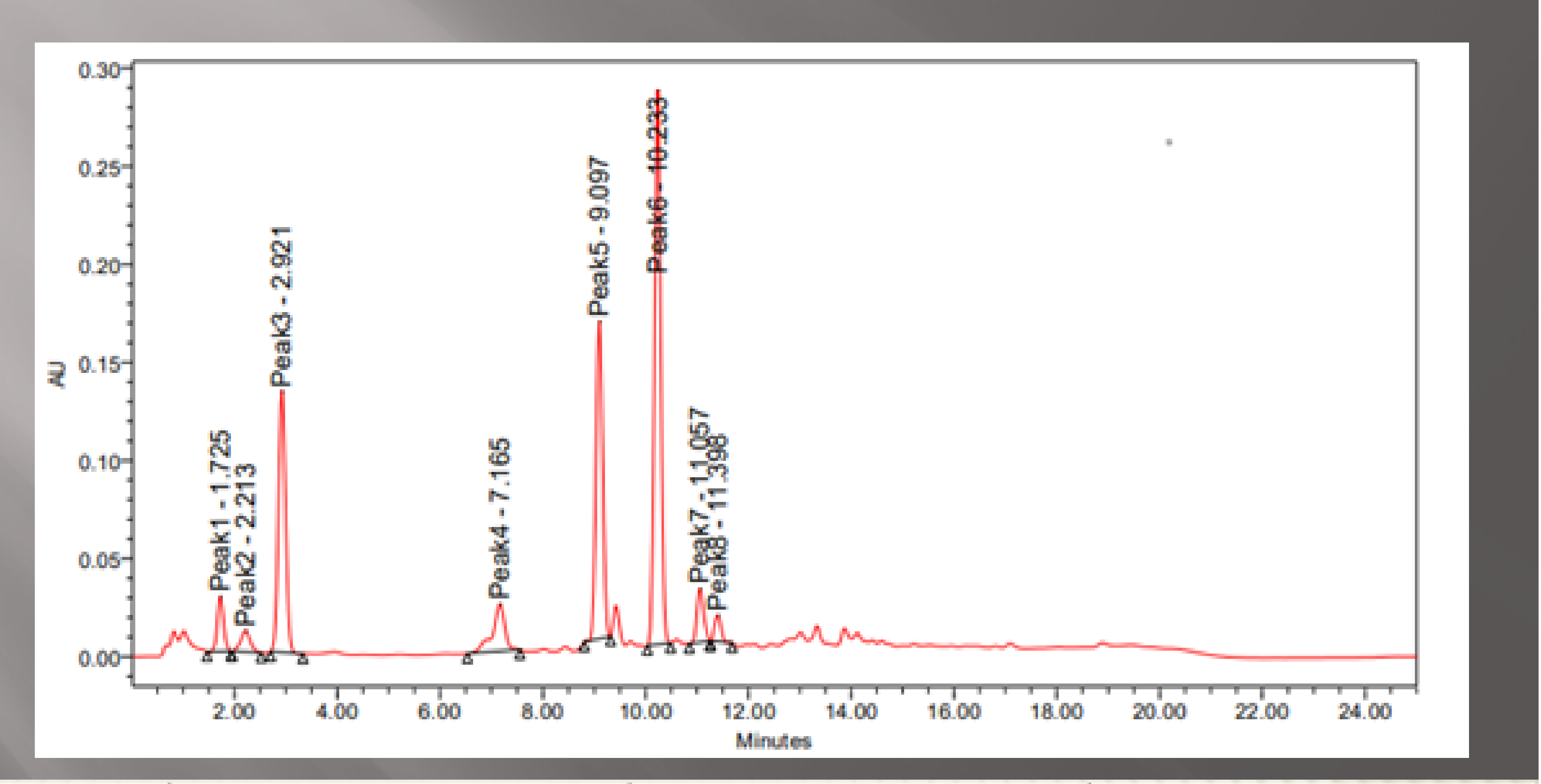

\begin{tabular}{|l|l|l|l|}
\multicolumn{1}{c|}{$\begin{array}{r}\text { Validation } \\
\text { parameters }\end{array}$} & $\begin{array}{r}\text { P-methoxy benzoic } \\
\text { acid }\end{array}$ & $\begin{array}{r}\text { P-hydroxy benzoic } \\
\text { acid }\end{array}$ & P-coumaric acid \\
\hline Linearity & $10-100 \mu \mathrm{g} / \mathrm{ml}$ & $20-120 \mu \mathrm{g} / \mathrm{ml}$ & $10-100 \mu \mathrm{g} / \mathrm{ml}$ \\
$\mathrm{R}^{2}$ & 0.999 & 0.989 & 0.999 \\
LOD & $2.19 \mu \mathrm{g} / \mathrm{ml}$ & $1.66 \mu \mathrm{g} / \mathrm{ml}$ & $0.982 \mu \mathrm{g} / \mathrm{ml}$ \\
LOQ & $1.83 \mu \mathrm{g} / \mathrm{ml}$ & $1.55 \mu \mathrm{g} / \mathrm{ml}$ & $1.234 \mu \mathrm{m} / \mathrm{ml}$ \\
Precision & $\% \mathrm{RSD}<2$ & $\% \mathrm{RSD}<2$ & $\% \mathrm{RSD}<2$ \\
Recovery & $93.07 \%$, & $95.24 \%$ & $99.11 \%$ \\
& & & \\
\hline
\end{tabular}

\begin{tabular}{|l|l|l|l|l|}
\hline S. No & Peak Nane & RT & Area & USP Tailing \\
\hline Reference values & & & \\
\hline 1 & PMBA & 2.125 & 685334.3 & 1.37 \\
\hline 2 & PHEA & 2.799 & 544097 & 2.54 \\
\hline 3 & PCA & 10.257 & 2360264 & 4.27 \\
\hline Ethanolic extract value & & & \\
\hline 4 & Peak2 & 2.144 & 439814 & 1.67 \\
\hline 5 & Peak3 & 2.789 & 344997 & 2.28 \\
\hline 6 & Peak6 & 10.233 & 2578264 & 4.78 \\
\hline \hline
\end{tabular}

\section{Conclusion:}

A simple and efficient HPLC method was developed for simultaneous identication and quantiation of PMBA, PHBA and $\mathrm{P}$ coumaric acid in ethanolic extract prepared from leaves V. trifolia. The developed HPLC method was validated as per ICH guidelines. The developed method is simple, precise and accurate and it can be used for recommended for routine and QC Analysis of Natural products.

\section{- References:}

- Sonal Shah, Tushar Dhanani, Satyanshu Kumar, HPLC method for identication and quantication of $p$-hydroxy benzoic acid and agnuside in Vitex negundo and Vitex trifolia, 2013;3(6):500-508.

- Ji-Hye Seo, Jung-Eun Kim,Jung-Hyun Shim,Goo Yoon, Mi-Ae Bang, Chun-Sik Bae, Kyung-Jin Lee,HPLC Analysis, Optimization of Extraction Conditions and Biological Evaluation of Corylopsis coreana Uyeki Flos; Molecules 2016, 21, 94 